\title{
DIVERSIDADE GENÉTICA DE Desmanthus virgatus L. EM SERGIPE
}

SOARES,Adrielle Naiana Ribeiro

Evandro Neves Muniz,

José Henrique Albuquerque Rangel,

Allivia Rouse Carregosa Rabbani,

Sílvio Gomes Santos,

Ana Veruska Cruz Silva

\begin{tabular}{lll}
\hline Recebido em: 2020.02 .21 & Aprovado em: 2020.06.19 & ISSUE DOI: $10.3738 / 1982.2278 .3743$ \\
\hline
\end{tabular}

RESUMO - A jureminha (Desmanthus virgatus L.) é uma leguminosa forrageira, nativa do Nordeste brasileiro. Em Sergipe é encontrada na zona da mata, agreste e no semiárido. É rica em proteína, sendo uma alternativa promissora para agropecuária. Os acessos mantidos em bancos de germoplasma são fontes de variabilidade genética para os programas de melhoramento, sendo a caracterização molecular importante ferramenta na identificação de duplicatas e seleção de genótipos. O objetivo do trabalho foi estimar a diversidade genética de Desmanthus virgatus L. nativos de mesorregiões do estado de Sergipe, Brasil. Foram utilizadas folhas jovens de 242 indivíduos, coletadas em três regiões ecogeográficas do estado de Sergipe (zona da mata, agreste e semiárido). Foram utilizados 16 iniciadores RAPD que geraram 109 fragmentos, com 96,33\% de polimorfismo. A maior variabilidade foi observada dentro das mesorregiões. Foi possível identificar onze grupos distintos por meio dos agrupamentos UPGMA e seis grupos pela ACoP. Por meio da análise bayesiana $(\mathrm{K}=4)$ verificou-se que existe mistura de material genético entre os acessos provenientes das regiões da zona da mata e agreste. Os marcadores utilizados foram eficientes para verificar a alta variabilidade genética existente em indivíduos de jureminha em Sergipe.

Palavras-chave: Jureminha, Marcadores RAPD, Germoplasma.

\section{GENETIC DIVERSITY OF Desmanthus virgatus L. IN SERGIPE}

SUMMARY - Jureminha (Desmathus virgatus L.) is forage legume from northeastern Brazil. In Sergipe is found in the forest zone, wild and semiarid. It is rich in protein, being a promising alternative for agriculture. The accessions in germplasm bank are sources of genetic variability for breeding programs, and molecular characterization is an important tool in the identification of duplicates and genotype selection. The objective was estimate the genetic diversity of Jureminha native from mesoregions of Sergipe State, Brazil. Young leaves of 242 individuals were collected from three ecogeographic regions of the state of Sergipe (zona da mata, agreste and semiarid). Sixteen RAPD primers that generated 109 fragments with $96.33 \%$ polymorphism were used. The highest variability was observed within the mesoregions. Eleven distinct groups were identified by UPGMA groupings and six groups by ACoP. Through the Bayesian analysis $(\mathrm{K}=4)$ it was verified that there is a mixture of genetic material between the accesses from the forest zone and the wild region. The markers used were efficient to verify the high genetic variability in individuals of Jureminha in Sergipe.

Keywords: Jureminha. Molecular Markers. Germplasm.

\section{INTRODUÇÃO}

O Nordeste brasileiro é considerado o centro de origem de diversas leguminosas (LOIOLA et al., 2010). Nesta região, a exploração desses vegetais consiste em um dos principais recursos para a produção de ruminantes, sendo a jureminha (Desmanthus virgatus L.) uma dessas espécies utilizadas na alimentação dos mesmos (CALADO et al., 2016).

O gênero Desmanthus é composto por 24 espécies de leguminosas, distribuídas em regiões tropicais e subtropicais das Américas, com maior diversidade no México, onde são encontradas 14 espécies, e sul do Texas, nos Estados Unidos, com oito espécies (MUIR et al., 2014). As espécies deste gênero são altamente selecionadas pelos animais, sendo consumidas na forma in natura ou de feno (SANTOS et al., 2010). No Nordeste há uma maior predominância de Desmanthus pernambucanus (L.) Thell. (PENGELLY; LIU, 2001), um arbusto resistente à seca e com alta eficiência na fixação biológica 
de nitrogênio (FREITAS et al., 2011). O valor nutricional é de 24-30\% de proteína em matéria seca, podendo ser utilizada para alimentar o rebanho durante o período de estiagem (FIGUEIREDO et al., 2000).

A maior parte das espécies de Desmanthus spp. é diploide, com 2n=28 (HUGHES et al., 2003). Estudos mais recentes ressaltaram que a espécie D. pernambucanus possui $2 \mathrm{n}=26$ e apresenta alto grau de polimorfismo intra e interespecífico (SANTOS et al., 2012), importante para a conservação da variabilidade genética da espécie (HUGHES et al., 2003).

Desta forma, a manutenção de um conjunto representativo de genótipos, por meio de bancos de germoplasma, é de fundamental importância para o estudo da variabilidade genética, seleção de genótipos promissores, desenvolvimento de estratégias de conservação e incorporação aos sistemas produtivos das regiões de ocorrência. Neste contexto, em 2011, A Universidade Federal Rural de Pernambuco criou, no município de Serra Talhada, PE, o banco de germoplasma com acessos de Desmanthus spp., coletados em 11 cidades do semiárido pernambucano (QUEIROZ, 2012). No ano de 2012, a mesma instituição criou o outro banco de germoplasma, em Carpina, PE, com sementes dos acessos do primeiro banco (DINIZ NETO et al., 2013). O conhecimento da variabilidade existente em bancos de germoplasma é fundamental para o melhoramento genético, uma vez que o estudo da diversidade entre acessos pode resultar em informações de pais com potencial para serem utilizados em programas de melhoramento. Desta forma, pode-se afirmar que a variabilidade genética, a seleção de indivíduos superiores e a avaliação de materiais promissores para a incorporação no setor comercial, são etapas primordiais em programas de melhoramento de plantas.

A utilização de marcadores moleculares, consiste em uma ferramenta para a identificação de genótipos, devido principalmente, a sua alta precisão em detectar diferenças a nível de DNA, destacandose a identificação e discriminação de genótipos. Os marcadores RAPD são dominantes e bastante utilizados devido principalmente ao seu baixo custo e eficiência em detectar a variabilidade existente. Apesar da sua importância, na literatura ainda há poucos trabalhos que abordam a diversidade genética jureminha, sendo primordial a caracterização da variabilidade para um futuro melhoramento genético da espécie.

O presente trabalho foi desenvolvido com o objetivo de estimar a diversidade genética de Desmanthus virgatus L. nativos de mesorregiões do Estado de Sergipe, Brasil.

\section{MATERIAL E MÉTODO}

Folhas jovens de 242 indivíduos foram coletadas de três regiões ecogeográficas do estado de Sergipe (zona da mata, agreste e semiárido) (Tabela 1). Após a extração do DNA [17], as amostras foram quantificadas em Nanodrop 2000c (Thermo Scientific, EUA) e armazenadas a $-20^{\circ} \mathrm{C}$ para uso subsequente nas reações de PCR. 
Tabela 1. Locais de coleta dos indivíduos nativos de jureminha, de acordo com as mesorregiões do estado de Sergipe.

\begin{tabular}{llcc}
\hline Mesorregião & \multicolumn{1}{c}{ Municípios de coleta } & $\begin{array}{c}\mathbf{N}^{\mathbf{0}} \text { de } \\
\text { indivíduos }\end{array}$ \\
\hline Zona da mata & Aracaju; Arauá; N.Sra. de Lourdes; Boquim; Cedro de São João; & 120 \\
& Cristinápolis; Estância; Ilha das flores; Itaporanga d'Ajuda; & \\
& Japaratuba; Japoatã; Pacatuba; Pedrinhas; Propriá; Riachuelo; & \\
& Rosário do Catete; S.L. do Itanhy; S.R.Lima; Salgado; São \\
& Cristovão; Umbaúba & \\
\hline Agreste & $\begin{array}{l}\text { Aquidabã; Campo do Brito; Itabaiana; Lagarto; Poço Verde; Riachão } \\
\text { do Dantas; Riachuelo; São Domingos Simão Dias; Tobias Barreto }\end{array}$ & 72 \\
\hline Semiárido & Carira; Feira Nova; Frei Paulo; Itabi; Monte Alegre; N.Sra. da & 50 \\
& Glória; Pinhão; Ribeirópolis; & & \\
\hline
\end{tabular}

Para os ensaios de PCR, foram utilizados 16 primers RAPD. O volume total da reação foi de $25 \mu \mathrm{L}$ contendo: $2 \mu \mathrm{L}$ da solução de DNA genômico, $2,5 \mu \mathrm{L}$ de primer, juntamente com um mix composto de $5 \mu \mathrm{L}$ de tampão PCR 10X; 0,5 $\mu \mathrm{L}$ de dntp $(10 \mathrm{mM}) ; 0,2$ de Taq DNA polimerase $(5 \mathrm{U} / \mu \mathrm{L})$ Invitrogen e $14,8 \mu \mathrm{L}$ de água ultrapura. Para amplificação das reações o termociclador (ProFlex ${ }^{\mathrm{TM}}$, Applied Biossystems, EUA) foi programado de forma que as amostras fossem desnaturadas a $95^{\circ} \mathrm{C}$ por cinco minutos, seguida por 45 ciclos de amplificação. A cada ciclo, as amostras sofreram em cadeia a desnaturação a $94^{\circ} \mathrm{C}$ por um minuto, anelamento a diferentes temperaturas por $45 \mathrm{~s}$ e, finalmente, extensão a $72^{\circ} \mathrm{C}$ por dois minutos.

$\mathrm{O}$ resultado da amplificação foi submetido à eletroforese horizontal, em gel de agarose a $2 \%$. Em seguida, os géis foram postos em contato, em uma solução contendo brometo de etídio $(0,5 \mu \mathrm{L} \mathrm{mL}-1$ de água), por 1 hora, e visualizados sob luz ultravioleta. Utilizou-se para a mensuração do padrão dos fragmentos o marcador de peso molecular de $1 \mathrm{~Kb}$, (Promega, Madison, South Dakota, EUA). A visualização dos resultados foi realizada em equipamento de fotodocumentação Gel doc L-pix (Loccus Biotecnologia, Cotia, SP).

Os fragmentos de RAPD foram convertidos em uma matriz binária, com base na presença (1) ou ausência (0) do fragmento. Os dados foram importados para o programa Genalex 6.5 e estimou-se a distribuição da variabilidade genética, tendo por base as variáveis: índice de Shannon (I); heterozigosidade esperada (He) e análise da variância molecular (AMOVA). Para estimar a distância genética de acordo com a similaridade de Jacard, utilizou-se o software PAST (HAMMER et al., 2001) e o respectivo dendograma foi formado com base no agrupamento UPGMA ("Unweighted Pair Group Method with Arithmetic Mean").

A consistência dos agrupamentos foi analisada por reamostragem "bootstrap", a 5000x. O método da análise de coordenadas principais (ACoP) foi realizado com o auxílio do software Genalex 6.5. Para analisar a diversidade genética associada à origem geográfica de cada acesso, foi utilizado o Programa Structure.

\section{RESULTADO E DISCUSSÃO}

Os 16 primers selecionados resultaram na amplificação de 109 fragmentos, com 96,33\% de polimorfismo. O número de fragmentos variou de 3 (IDT20) a 10 (W02) (Tabela 2). Os valores 
encontrados neste trabalho são semelhantes a outros estudos utilizando marcadores dominantes em Desmanthus sp. (COSTA et al., 2017), e em Croton tetradenius (ALMEIDA-PEREIRA et al., 2017). Apesar de ser bastante utilizado em trabalho de diversidade genética, a porcentagem de locos polimórficos são bastante variáveis (SOARES et al., 2016), já que o polimorfismo pode variar em função dos genótipos avaliados (ARAÚJO et al., 2016).

Tabela 2. Primers RAPD utilizados para estimar a diversidade genética de indivíduos de jureminha oriundos de três microrregiões de Sergipe (Agrestre, Semiárido e Zona da Mata),com suas respectivas sequências e número total de fragmentos (TF), número de fragmentos polimórficos (FP) e porcentagem de polimorfismo (PP).

\begin{tabular}{cccc}
\hline Sequência & $\begin{array}{c}\text { Total de } \\
\text { fragmentos } \\
\text { Primers RAPD }\end{array}$ & $\begin{array}{c}\text { Fragmentos } \\
\text { polimórficos } \\
\text { (FP) }\end{array}$ & $\begin{array}{c}\text { PPF } \\
(\text { \%) }\end{array}$ \\
\hline A01 & 9 & 9 & 100 \\
A04 & 8 & 8 & 100 \\
A08 & 6 & 6 & 100 \\
A10 & 8 & 8 & 100 \\
A13 & 8 & 7 & 87.5 \\
B02 & 7 & 7 & 100 \\
B18 & 4 & 4 & 100 \\
IDT02 & 5 & 5 & 100 \\
IDT15 & 4 & 2 & 50 \\
IDT20 & 3 & 3 & 100 \\
K20 & 8 & 8 & 100 \\
S01 & 7 & 7 & 100 \\
S18 & 6 & 6 & 100 \\
W02 & 10 & 9 & 89 \\
W13 & 8 & 8 & 100 \\
W19 & 8 & 8 & 100 \\
\hline
\end{tabular}

Fonte: Elaborado pelos Autores

A partir de 75 fragmentos houve estabilização do coeficiente de variação, com valor inferior a 10\%, indicando que os valores obtidos são confiáveis para o estudo de diversidade genética entre os acessos (Figura 1). A indicação do número mínimo de bandas em estudos de diversidade genética contribui para a otimização do uso de recursos e tempo, sendo necessária uma menor quantidade de marcadores representativos para caracterização da diversidade genética (GONÇALVES et al., 2014). 
Figura 1. Coeficiente de variação para o número de fragmentos polimórficos utilizando marcadores RAPD entre indivíduos de jureminha oriundos de três microrregiões de Sergipe (Agrestre, Semiárido e Zona da Mata), Brasil.

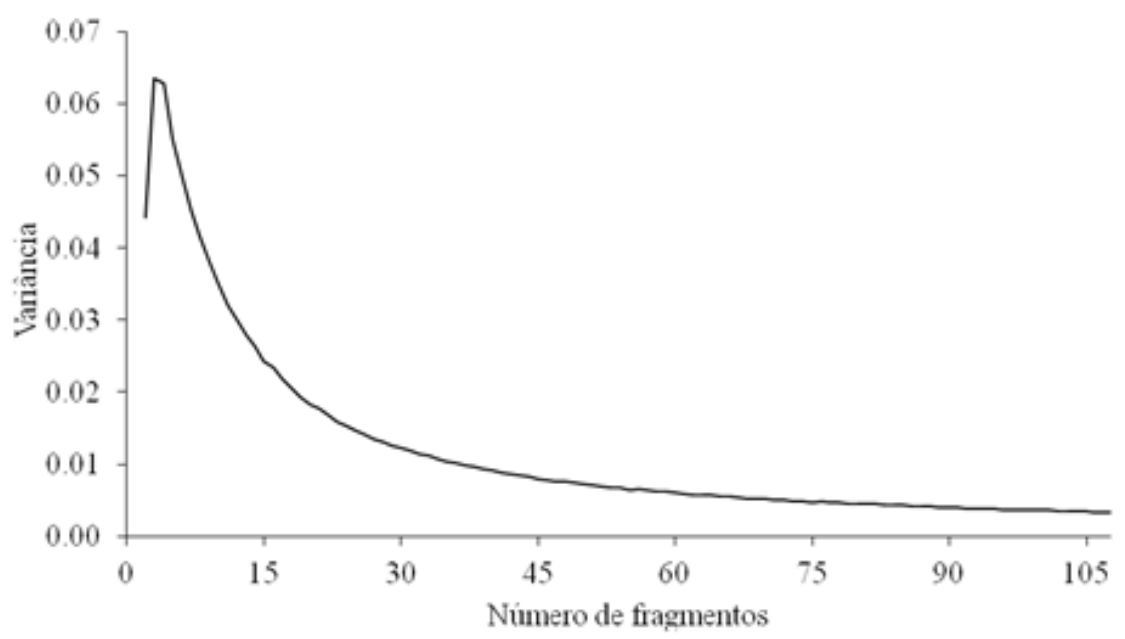

Fonte: Elaborado pelos Autores

O baixo valor de He médio $(0,25)$ para sugere baixa diversidade entre os indivíduos. O índice de Shannon (I) é um indicador de diversidade, que varia de 0 a 1 , e que, quanto mais próximo de zero, menor será a diversidade. Nesse estudo o valor médio foi de 0,38 , e indica baixa diversidade (Tabela 3 ). Resultados semelhantes foram observados utilizando marcadores AFLP entre acessos de Desmanthus sp., com He de 0,29, indicando baixa diversidade genética (QUEIROZ, 2012).

Tabela 3. Número de indivíduos (N), índice de Shannon (I) e Heteroziosidade esperada (He), para indivíduos de jureminha oriundos de três microrregiões de Sergipe (Agrestre, Semiárido e Zona da Mata), Brasil.

\begin{tabular}{ccc}
\hline Acessos & I & He \\
\hline RPP1 & 0,42 & 0,28 \\
RPP2 & 0,43 & 0,29 \\
RPP3 & 0,35 & 0,24 \\
RPP4 & 0,32 & 0,21 \\
\hline Média & 0,38 & 0,25 \\
\hline
\end{tabular}

Fonte: Elaborado pelos Autores

Estes resultados provavelmente estão ligados ao sistema de reprodução da espécie, que pode influenciar na diversidade genética entre indivíduos (SOARES et al., 2016). A autogamia presente nesta espécie possivelmente impede ou dificulta a troca de material genético entre os acessos, o que pode explicar a baixa diversidade genética.

A partir da matriz de dissimilaridade foi possível destacar 20 valores com menores e maiores índices (Tabela 4). O cruzamento entre os indivíduos J7xJ8 e J61xJ164 estabeleceram a maior e menor similaridade, 0,98 e 0,30, respectivamente. Os menores índices de similaridades ocorreram entre indivíduos de um mesmo acesso, e os maiores índices entre indivíduos de acessos diferentes. Os pares com maiores similaridades não são recomendados para programas de melhoramento genético, pois há maior tendência de haver restrição nos ganhos obtidos por seleção. 
Tabela 4. Maiores e menores valores de similaridade genética, baseados no índice de similaridade de Jaccard, calculado a partir de 16 iniciadores RAPD em indivíduos de jureminha oriundos de três microrregiões de Sergipe (Agrestre, Semiárido e Zona da Mata), Brasil.

\begin{tabular}{|c|c|c|c|c|}
\hline \multirow[t]{2}{*}{ Ordem } & Maiores similaridades & \multicolumn{3}{|c|}{ Menores similaridades } \\
\hline & Indivíduos & $\mathrm{s}$ & Indivíduos & $\mathrm{s}$ \\
\hline 1 & J7 (N.Sra. Lourdes, ZM) x J37 (Ribeirópolis/SA) & 0,70 & $\mathrm{~J} 52 \mathrm{xJ} 123$ & 0,11 \\
\hline 2 & J10 (N.Sra. Lourdes/ZM) x J25 (N.Sra. Glória/SA) & 0,72 & $\mathrm{~J} 52 \mathrm{xJ} 156$ & 0,12 \\
\hline 3 & J17(Itabi/SA) x J14 (Cedro de São João/ZM) & 0,74 & $\mathrm{~J} 52 \mathrm{xJ} 126$ & 0,13 \\
\hline 4 & J16 (Muribeca/AG) x J22 (N.Sra.Dores/AG) & 0,75 & $\mathrm{~J} 73 \mathrm{xJ} 242$ & 0,14 \\
\hline 5 & J18(Feira Nova/AS) x J22 (N.Sra.Dores/AG) & 0,76 & $\mathrm{~J} 64 \mathrm{xJ} 210$ & 0,15 \\
\hline 6 & J10 (N.Sra.Lourdes/ZM) x J14 (Cedro/ZM) & 0,77 & $\mathrm{~J} 64 \mathrm{xJ} 127$ & 0,16 \\
\hline 7 & J13 (Propriá/ZM) x J17 (Itabi/SA) & 0,78 & $\mathrm{~J} 23 \mathrm{xJ} 233$ & 0,17 \\
\hline 8 & J1 (São Domingos/AG) x J10 (N.Sra. Lourdes (ZM) & 0,79 & $\mathrm{~J} 75 \mathrm{xJ} 241$ & 0,18 \\
\hline 9 & J4 (Itabi/AS) x J10 (N.Sra.Lourdes/ZM) & 0,80 & $\mathrm{~J} 76 \mathrm{xJ} 222$ & 0,19 \\
\hline 10 & J16 (Muribeca /AG) x J10 (N.Sra. Lourdes/ZM) & 0,81 & $\mathrm{~J} 52 \mathrm{xJ} 236$ & 0,20 \\
\hline 11 & J9 (N.Sra. Lourdes/ZM) x J10 (N.Sra. Lourdes/ZM) & 0,82 & J6xJ167 & 0,21 \\
\hline 12 & J3 Itabi/AS) x J9 (N. Sra Lourdes (ZM) & 0,83 & $\mathrm{~J} 22 \mathrm{xJ} 242$ & 0,22 \\
\hline 13 & J3 (Monte Alegre/SA) x J5(Itabi/SA) & 0,84 & $\mathrm{~J} 28 \mathrm{xJ} 228$ & 0,23 \\
\hline 14 & J4 (Itabi/AS) xJ9 (N.Sra. Lourdes/ZM) & 0,86 & J9xJ228 & 0,24 \\
\hline 15 & J7 (N.Sra. Lourdes/ZM) x J4 (Itabi/SA) & 0,90 & $\mathrm{~J} 14 \mathrm{xJ} 225$ & 0,25 \\
\hline 16 & J3 (Monte Alegre/SA) x J2 (Porto da Folha/SA) & 0,91 & $\mathrm{~J} 68 \mathrm{xJ} 215$ & 0,26 \\
\hline 17 & J5 (Itabi/SA)X J8 (N.Sra. Lourdes/ZM) & 0,92 & J77xJ206 & 0,27 \\
\hline 18 & J5 (Itabi/SA) x J6 (Itabi/SA) & 0,93 & $\mathrm{~J} 61 \times \mathrm{xJ} 210$ & 0,28 \\
\hline 19 & J7 (N.Sra. Lourdes/ZM) x J26 (N.Sra. Glória/SA) & 0,94 & $\mathrm{~J} 57 \mathrm{xJ} 215$ & 0,29 \\
\hline 20 & J7 (N.Sra. Lourdes/ZM) x J8 (N.Sra. Lourdes/ZM) & 0,98 & J61xJ164 & 0,30 \\
\hline
\end{tabular}

* AG. Agreste; SA.Semiárido; ZM. Zona da Mata.

Fonte: Elaborado pelos Autores

As estimativas das distâncias genéticas, avaliadas por meio de um dendograma, permitiram a formação de onze grupos distintos, pelo método UPGMA (Figura 2). O maior grupo (G3) foi constituído por 41 acessos, oriundos das regiões agreste e zona da mata. O grupo G2 foi o mais divergente, sendo formados por 33 acessos originários das regiões agreste, semiárido e zona da mata. Os menores grupos (G1 e G10) foram formados por apenas dois acessos cada. A formação de poucos grupos pode ser um indicativo de baixa diversidade genética, que pode está ligado à base genética estreita da espécie (FONTENELE et al., 2009). 
Figura 2. Representação filogenética pelo agrupamento UPGMA para 242 indivíduos de jureminha oriundos de três microrregiões de Sergipe (Agrestre, Semiárido e Zona da Mata), Brasil.

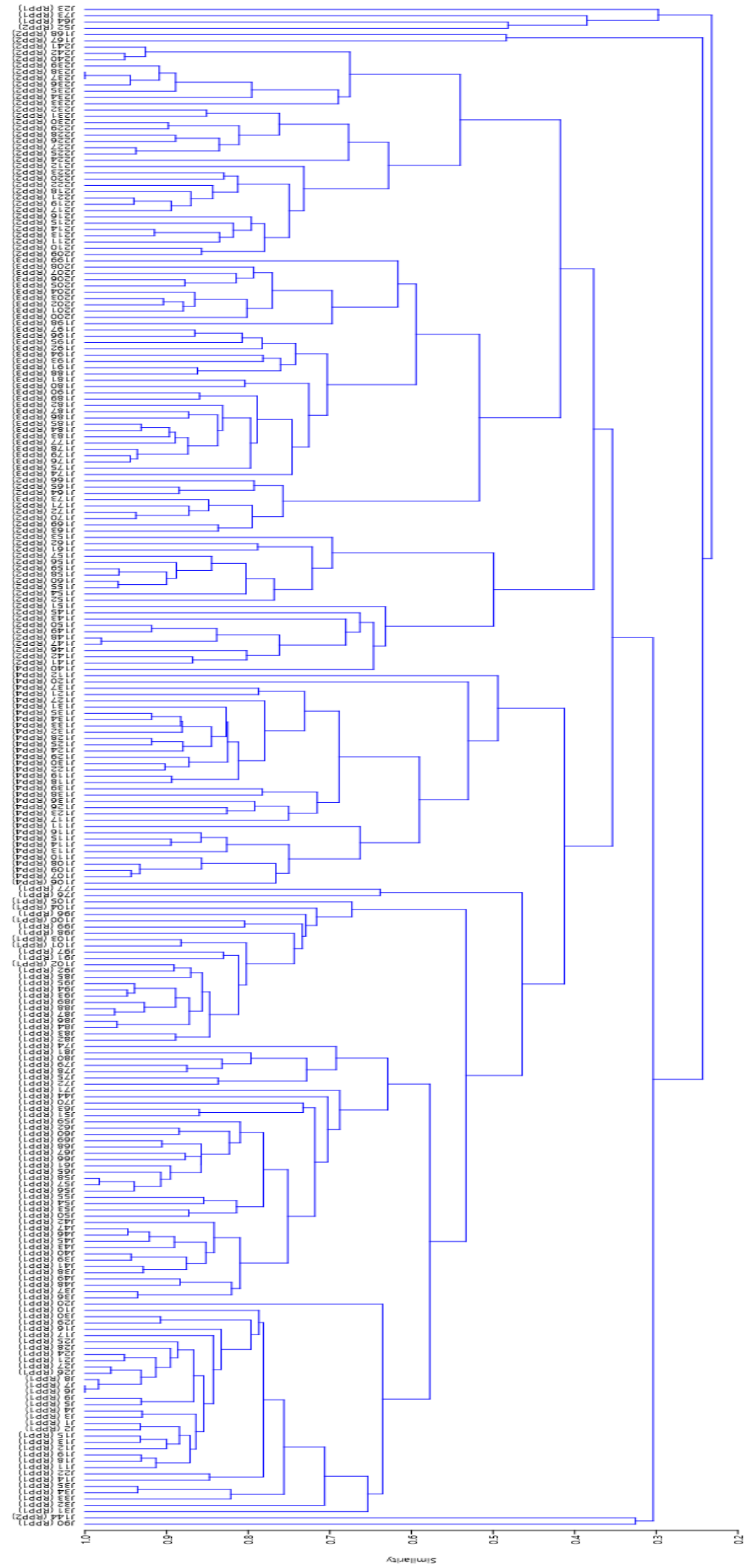

Fonte: Elaborado pelos Autores 
As distâncias genéticas também foram avaliadas pela Análise de Coordenadas Principais (ACoP) (Figura 3). Foram identificados seis grupos, e os dois componentes principais explicaram $35 \%$ da variação. De maneira geral, houve semelhança entre os grupos formados pelos métodos UPGMA e ACoP, confirmando a associação entre os acessos nos agrupamentos.

Os diferentes métodos de agrupamentos utilizados auxiliam para que haja uma melhor distinção dos grupos formados, podendo indicar novos estudos entre indivíduos mais divergentes, assim, é importante que mais de um método de agrupamento seja utilizado para que haja menor erro na classificação entre os grupos (ARRIEL et al., 2006). Os resultados verificados para os métodos utilizados nesta pesquisa evidenciaram que os marcadores RAPD foram eficientes na caracterização da diversidade genética entre acessos de jureminha.

Figura 3. Análise de coordenadas principais $(\mathrm{ACOP})$ para indivíduos de jureminha oriundos de três microrregiões de Sergipe (Agrestre, Semiárido e Zona da Mata), Brasil.

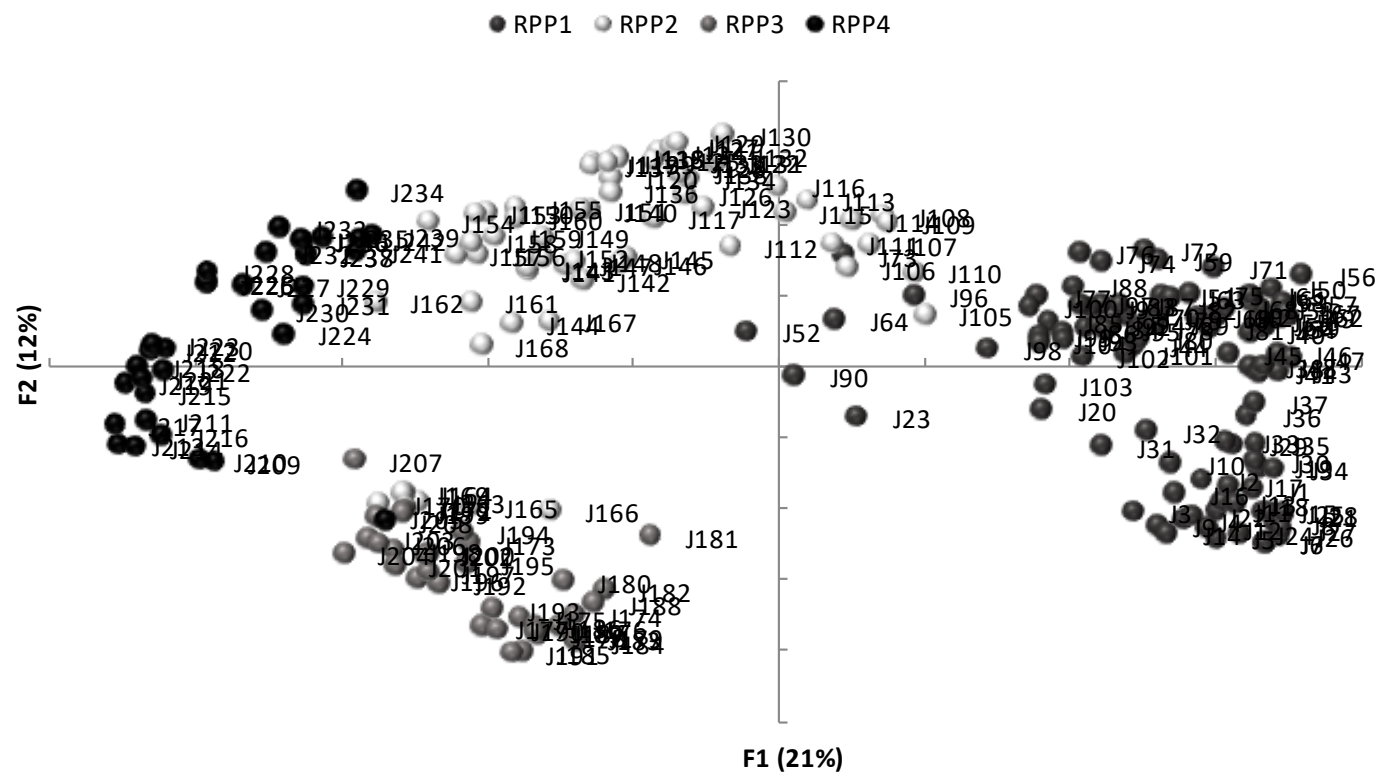

Fonte: Elaborado pelos Autores

De acordo com a análise de variância molecular (AMOVA), a maior parte da variabilidade foi observada dentro das mesorregiões onde foram coletados os indivíduos. Apesar disso, a variabilidade entre elas foi significativa (Tabela 4). A maior variabilidade dentro dos grupos avaliados pode reduzir a possibilidade de deriva genética e da endogamia, e assim, contribuir para a manutenção da diversidade genética.

A distribuição da variação genética dentro de populações não é aleatória, e sim determinada por alguns fatores, como o sistema reprodutivo, a distribuição geográfica da espécie, o tamanho efetivo das populações e fluxo gênico (HAMRICK, 1983). A troca de material genético entre indivíduos pode ocorrer por meio de polinizadores e dispersores de sementes, sendo importante o conhecimento de mecanismos de polinização e dispersão de sementes que ocorrem na espécie 
(ROCHA et al., 2016). Além disso, outro ponto essencial é o conhecimento do sistema de reprodução da espécie, que causa influência na variabilidade genética, tanto homogeneizando quanto aumentando a divergência entre indivíduos e populações (ZANELLA et al., 2016). O estudo da distribuição espacial nas populações de $D$. virgatus irá contribuir para a seleção de material genético a ser utilizado em programas de melhoramento e conservação de recursos genéticos.

Tabela 4. Análise de variância molecular (AMOVA) entre e dentro das mesorregiões (Agrestre, Semiárido e Zona da Mata) de onde foram coletados os indivíduos de jureminha, em Sergipe.

\begin{tabular}{cccccc}
\hline Fonte de variação & df & SS & MS & Est. Var. & \% \\
\hline Entre as mesorregiões & 3 & 1608 & 536 & 9 & $41 \%$ \\
Dentro das mesorregiões & 238 & 3177 & 13 & 13 & $59 \%$ \\
\hline Total & 241 & 4786 & & 23 & $100 \%$ \\
\hline
\end{tabular}

Fonte: Elaborado pelos Autores

Os padrões genéticos de diferenciação e estruturação populacional dos acessos podem ser verificados por meio da análise bayesiana, que mostrou um valor máximo de $\mathrm{K}=4$ (Figura 4). A visualização gráfica permitiu identificar que existe uma mistura de material genético entre os acessos provenientes das regiões da zona da mata e agreste, o que pode indicar que nestas áreas há intercâmbio de material genético entre as plantas.

Figura 4. Inferência Bayesiana para os indivíduos de jureminha oriundos de três microrregiões de Sergipe (Agrestre, Semiárido e Zona da Mata), com K=4.

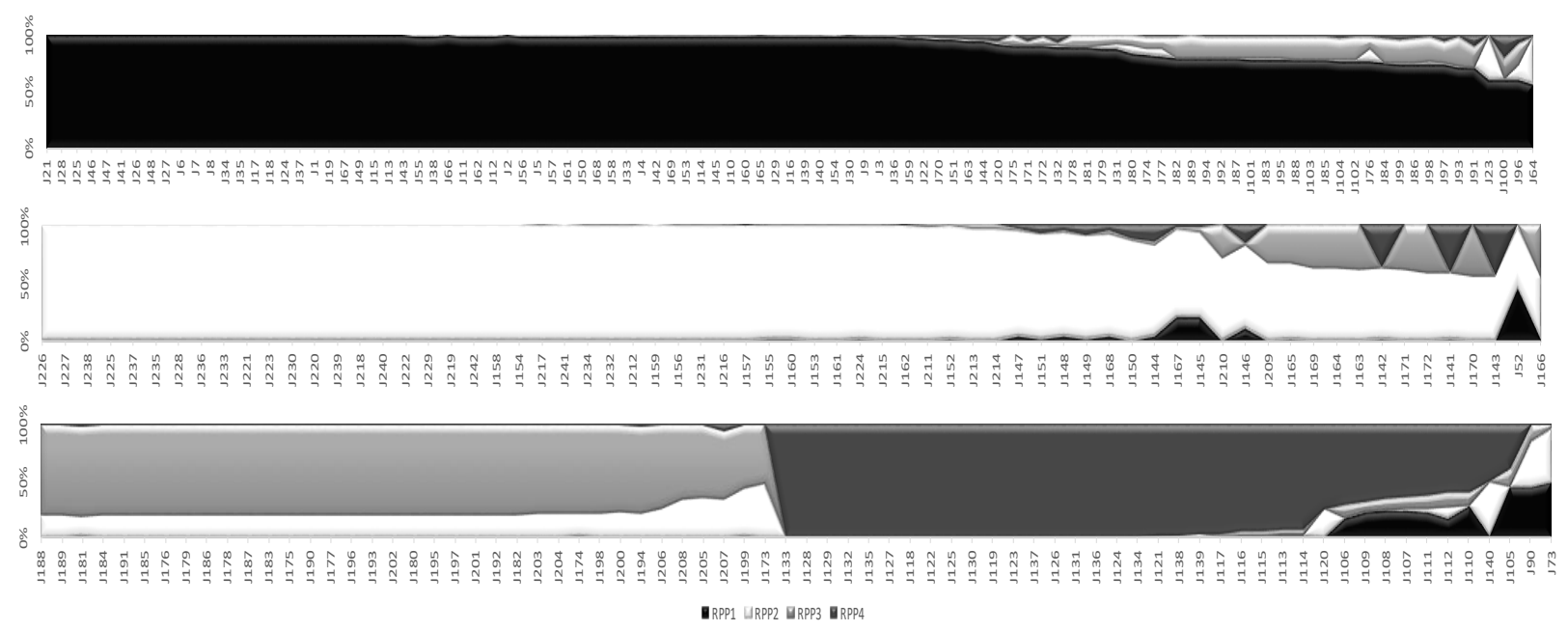

Fonte: Elaborado pelos Autores

No semiárido nordestino, a principal forma de exploração das forrageiras nativas é por meio do extrativismo, prática que pode levar ao uso irracional dos recursos naturais existentes e contribuir para que haja acelerada erosão genética das espécies. Embora o Brasil seja um centro de diversificação de leguminosas forrageiras, este potencial permanece ainda pouco utilizado, principalmente devido a falta de conhecimento das espécies.

Apesar da importância da jureminha na região do semiárido nordestino, o conhecimento sobre as características ecológicas e genéticas ainda são incipientes. Neste cenário, o estudo da diversidade 
genética constitui-se como uma ferramenta essencial, contribuindo para o conhecimento das relações entre os genótipos, caracterização e obtenção de genótipos superiores em gerações segregantes.

\section{CONCLUSÃO}

Os marcadores utilizados neste estudo foram eficientes para estimar a alta variabilidade genética de acessos de Desmanthus virgatus L. em Sergipe.

\section{REFERÊNCIAS}

ALMEIDA-PEREIRA, C.S.; SILVA, A.V.C.; ALVES, R.P.; FEITOSA-ALCANTARA, R.B.; ARRIGONI-BLANK, M.F.; ALVES-CARVALHO, S.V.; COSTA, T.S.; WHITE, L.A.S.; PINTO, V.S.; SAMPAIO, T.S.; BLANK, A.F. Genetic diversity of native populations of Croton tetradenius Baill. using ISSR markers. Genetics and Molecular Research. v.16, n.2, p.16029602, 2017. doi: http://dx.doi.org/10.4238/gmr16029602

ARAÚJO, F.S.; PACHECO, M.V.; VIEIRA, F.A.; FERRARI, C.B.; FÉLIX, F.C.; CHAGAS, K.P.T. ISSR molecular markers for the study of the genetic diversity of Mimosa caesalpiniaefolia Benth. Idesia, v.34, n.3, p. 47-52, 2016. doi: http://dx.doi.org/10.4067/S0718$\underline{34292016000300007}$

ARRIEL, N.H.C.; DI MAURO, A.O.; DI MAURO, S.M.Z.; BAKKE, O.A.; UNÊDATREVISOLI, S.H.; COSTA, M.M.; CAPELOTO, A.; CORRADO, A.R. Técnicas multivariadas na determinação da diversidade genética em gergelim usando marcadores RAPD. Pesquisa Agropecuária Brasileira, v.41, p.801-809, 2006. doi: http://dx.doi.org/10.1590/S0100$\underline{\text { 204X2006000500012 }}$

CALADO, T.B.; CUNHA, M.V.; TEIXEIRA, V.B.; SANTOS, M.V.F.; CAVALCANTI, H.S.; LIRA, C.C. Morphology and productivity of "jureminha" genotypeS (Desmanthus spp.) under different cutting intensities. Revista Caatinga, v.29, n.3, p.742 - 752, 2016. doi:

http://dx.doi.org/10.1590/1983-21252016v29n326rc

COSTA, J.C.; FRACETTO, G.G.M.; FRACETTO, F.J.C.; SANTOS, M.V.F.; LIRA JÚNIOR, M.A. Genetic diversity of Desmanthus sp accessions using ISSR markers and morphological traits. Genetics and Molecular Research, v.16, n.2, p.1602-9667, 2017.

http://dx.doi.org/10.4238/gmr16029667

DINIZ NETO, M.A.; VASCONCELOS, R.C.M.; CAVALCANTE, L.F.; PIMENTA FILHO, E.C. Disponibilidade de dois solos e diferentes idades de corte no comportamento agronômico de Jureminha. Revista Ciência Agronômica, v.44, p.24-33, 2013. doi: https://doi.org/10.1590/S1806-66902013000100004

DOYLE, J.J.; DOYLE, J.L. Isolation of plant DNA from fresh tissue. Focus, v.12, p. 13-15, 1990.

FIGUEIREDO, M.V.; GUIM, A.; PIMENTA FILHO, E.C.; SARMENTO, J.L.R.; ANDRADE, M.V.M.; PINTO, M.S.C.; LIMA, J.A. Estudo descritivo de Desmanthus virgatus: uma revisão. In: CONGRESSO NORDESTINO DE PRODUÇÃO ANIMAL, 2 Anais [...]; 2000, Teresina, SNPA, v. 2. p. 341-344, 2000. 
FONTENELE, A.C.F.; ARAGÃO, W.M.; RANGEL, J.H.A.; ALMEIDA, S.A. Leguminosas tropicais: Desmanthus virgatus (1.) willd. Uma forrageira promissora. Revista Brasileira de Agrociência, v.15, n.1, p.121-123, 2009. doi:http://dx.doi.org/10.18539/cast.v15i1-4.1998

FREITAS, A.D.S.; SILVA, T.O.; MENEZES, R.S.C.; SAMPAIO, E.V.S.B.; ARAÚJO, E.R.; FRAGA, V.S. Nodulação e fixação de nitrogênio por forrageiras da caatinga cultivadas em solos do semiárido paraibano. Revista Brasileira de Zootecnia, v.40, n.9, p.1856-1861, 2011. doi: http://dx.doi.org/10.1590/S1516-35982011000900002

GONÇALVES, L.O.; PINHEIRO, J.B.; ZUCCHI, M.I.; SILVA-MANN, R. Caracterização genética de mulungu (Erythrina velutina Willd.) em áreas de baixa ocorrência. Revista Ciência Agronômica, v.45, n.2, p.:290-298, 2014. doi: http://dx.doi.org/10.1590/S1806$\underline{66902014000200009}$

HAMMER, Ø; HARPER, D.A.T.; RYAN, P.D. Past: paleontological statistics software package for education and data analysis. Palaeontologia Electronica, v. 4, n.1, p.1-9, 2011.

HAMRICK, J.L. The distribution of genetic variation within and among natural plant populations. In: SHONEWALD-COX, C.M.; CHAMBERS, S.M.; MacBIDE, B.; THOMAS, W.L. (Ed.). Genetics and conservation: a reference for managing wild animal and plant population. Menlo Park: Benjamin/Cummings, 1983. 335-348.

HUGHES, C.E.; BAILEY, C.D.; KROSNICK, S.; LUCROW, M.A. Relationships among genera of the informal Dischroschys and Leucena groups (Mimosoideae) inferred from nuclear ribosomal ITS sequences. Royal Botanic Gardens, Advances in Legume Systematics; p. $221-238,2003$

LOIOLA, M.B.; PATERNO, G.B.C.; DINIZ, J.A.; CALADO, J.F.; OLIVEIRA, A.C.P. Leguminosas e seu potencial de uso em comunidades rurais de São Miguel do Gostoso - RN. Revista Caatinga, v.23, n.3, p. 59-70, 2010. https://periodicos.ufersa.edu.br/index.php/caatinga/article/view/1741

PENGELLY, B.C.; LIU, C.J. Genetic relationships and variation in the tropical mimosoid legume Desmanthus assessed by random amplified polymorphic DNA. Genetic Resources and Crop Evolution, 2001; v.48, n.1, p.93-101, 2001. doi: https://doi.org/10.1023/A:1011234913710

QUEIROZ, I.V. Ocorrência e germinação de sementes de Desmanthus sp. coletadas no semiárido pernambucano. Master's thesis. Recife (PE): Universidade Federal Rural de Pernambuco; 2012. $80 \mathrm{f}$.

ROCHA, T.O.; FREITAS, J.S.; SANTOS, E.S.L.; SCALDAFERRI, M.M.; OLIVEIRA, C.G.; CERQUEIRA-SILVA, C.B.M. Estimate of genetic diversity in cassutinga (Croton heliotropiifolius) based on molecular markers. African Journal of Biotechnology, v.15, n. 13, p.518-523, 2016. doi: http://dx.doi.org/10.5897/AJB2015.15009

SANTOS, E.C.X.R.; CARVALHO, R.; ALMEIDA, E.M.; FELIX, LP. Chromosome number variation and evolution in Neotropical Leguminoseae (Mimosoideae) from northeastern Brazil. Genetics and Molecular Research, v.11, n.3, p. 2451-2475, 2012.

SANTOS, M.V.F.; LIRA, M.A.; DUBEUX JÚNIOR, J.C.B.; GUIM, A.; MELLO, A.C.L.; CUNHA, M.V. Potential of Caatinga forage plants in ruminant feeding. Revista Brasileira de Zootecnia, v. 39, p.204-215.2010. doi: http://dx.doi.org/10.1590/S1516-35982010001300023 
SOARES, A.N.R.; VITÓRIA, M.F.; NASCIMENTO, A.L.S.; LEDO, A.S.; RABBANI, A.R.C.; SILVA, A.V.C. Genetic diversity in natural populations of mangaba in Sergipe, the largest producer State in Brazil. Genetics and Molecular Research, v.15, n.3, p.1503-8624, 2016. doi: http://dx.doi.org/10.4238/gmr.15038624

ZANELLA, C.M.; JANKE, A.; PALMA-SILVA, C.; KALTCHUK-SANTOS, E.; PINHEIRO, F.G.; PAGGI, G.M.; SOARES, L.E.S.; GOETZE, M.; BUTTOW, M.; BERED, F. Genetics, evolution and conservation of Bromeliaceae. Genetic and Molecular Biololgy, v.35, n.4, p. 1020-1026, 2016. doi: http://dx.doi.org/10.1590/S1415-47572012000600017 